\title{
Recurrent hypocalcaemic torsades de pointes due to hungry bone syndrome: a rare complication of thyroidectomy
}

\author{
Q. A. J. Hagdorn · P. Loh · S. Velthuis
}

Accepted: 16 December 2020 / Published online: 4 January 2021

(c) The Author(s) 2020

A 49-year-old, otherwise healthy female was admitted to our hospital for thyroidectomy. Postoperatively, presumably due to perioperative hypoperfusion of the parathyroid glands, she developed 'hungry bone syndrome', which is characterised by suppressed parathyroid hormone levels, resulting in an increased net bone uptake of calcium and subsequent severe hypocalcaemia [1]. Even with intravenous calcium supplementation, she developed QT prolongation and multiple episodes of torsades de pointes (TdP) ventricular tachycardia without cardiac output (Fig. 1). Isoprenaline was started to increase her heart rate to prevent further TdP. However, despite adequate heart rates (70-100 beats/min) and increasing, yet still subnormal, calcium levels, sustained TdP repeatedly developed, requiring electrocardioversion. She was transferred to a tertiary clinic, where her rhythm was successfully controlled by temporary tachypacing and high-dose beta-blockers. Chronic calcium supplementation eventually normalised her calcium levels and QT time.

Even though hypocalcaemia-induced TdP rarely complicates thyroidectomy [2-4], this case demonstrates the value of electrocardiographic and electrolyte screening after thyroidectomy and rhythm surveillance in severe hypocalcaemia.

Conflict of interest Q.A.J. Hagdorn, P. Loh and S. Velthuis declare that they have no competing interests.
Open Access This article is licensed under a Creative Commons Attribution 4.0 International License, which permits use, sharing, adaptation, distribution and reproduction in any medium or format, as long as you give appropriate credit to the original author(s) and the source, provide a link to the Creative Commons licence, and indicate if changes were made. The images or other third party material in this article are included in the article's Creative Commons licence, unless indicated otherwise in a credit line to the material. If material is not included in the article's Creative Commons licence and your intended use is not permitted by statutory regulation or exceeds the permitted use, you will need to obtain permission directly from the copyright holder. To view a copy of this licence, visit http://creativecommons.org/licenses/by/4.0/.

\section{References}

1. Jain N, ReillyRF. Hungrybonesyndrome. CurrOpin Nephrol Hypertens. 2017;26:250-5.

2. Falch C, Hornig J, Senne M, Braun M, Konigsrainer A, Kirschniak A, et al. Factors predicting hypocalcemia after total thyroidectomy-A retrospective cohort analysis. Int J Surg. 2018;55:46-50.

3. Karunakaran P, Maharajan C, Ramalingam S, Rachmadugu SV. Is hungry bone syndrome a cause of postoperative hypocalcemia after total thyroidectomy in thyrotoxicosis? A prospective study with bone mineral density correlation. Surgery. 2018;163:367-72.

4. Kusuki K, Mizuno Y. Hungry bone syndrome after thyroidectomy for thyroid storm. BMJ Case Rep. 2019;12(10):e231411. https://doi.org/10.1136/bcr-2019231411.

\footnotetext{
Q. A. J. Hagdorn $(\varangle) \cdot$ S. Velthuis

Department of Cardiology, Meander Medical Center,

Amersfoort, The Netherlands

qaj.hagdorn@meandermc.nl

P. Loh

Department of Cardiology, University Medical Center

Utrecht, Utrecht University, Utrecht, The Netherlands
} 


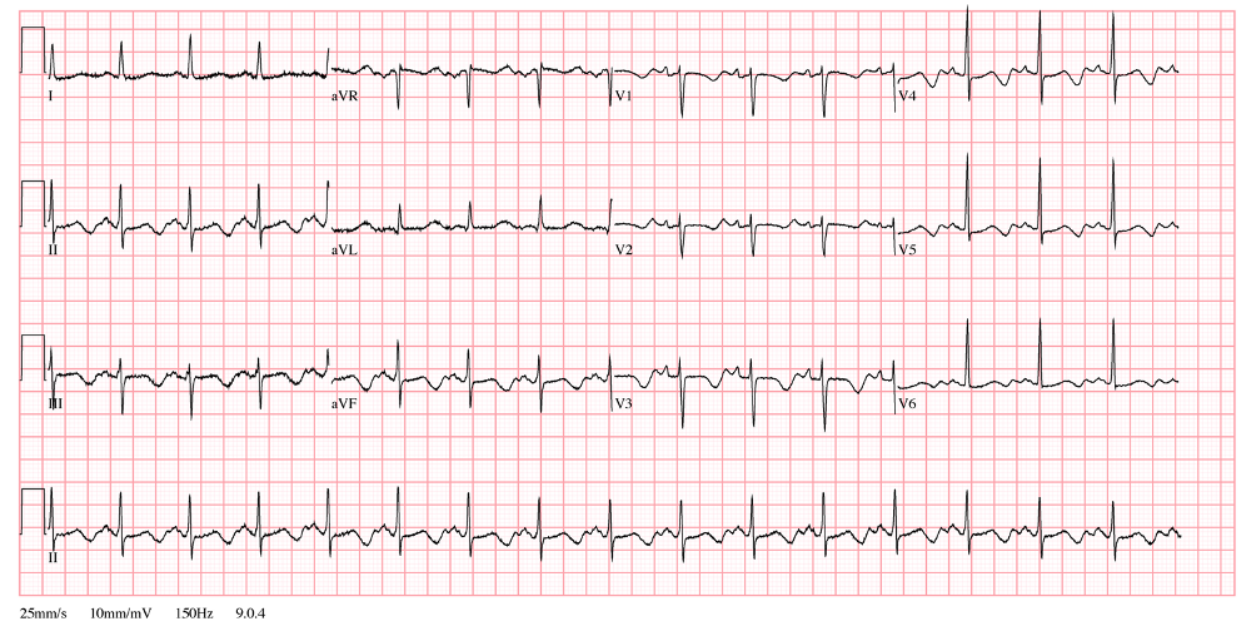

\section{ECG measurements}

Heartrate $\quad 96$ beats $/ \mathrm{min}$

PR interval $\quad 128 \mathrm{~ms}$

QRS duration $\quad 87 \mathrm{~ms}$

QT interval $\quad 440 \mathrm{~ms}$

QTc interval $\quad 557 \mathrm{~ms}$

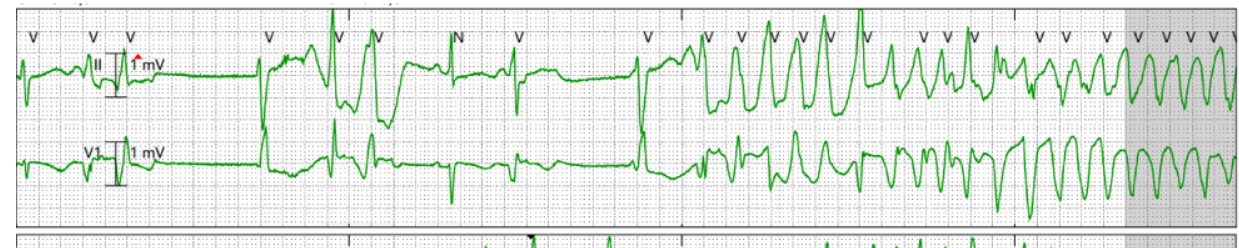

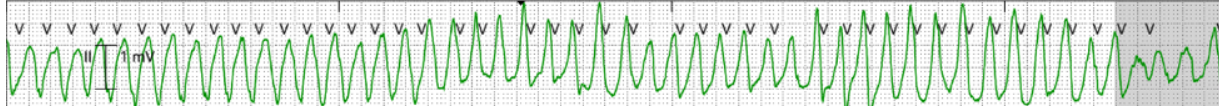
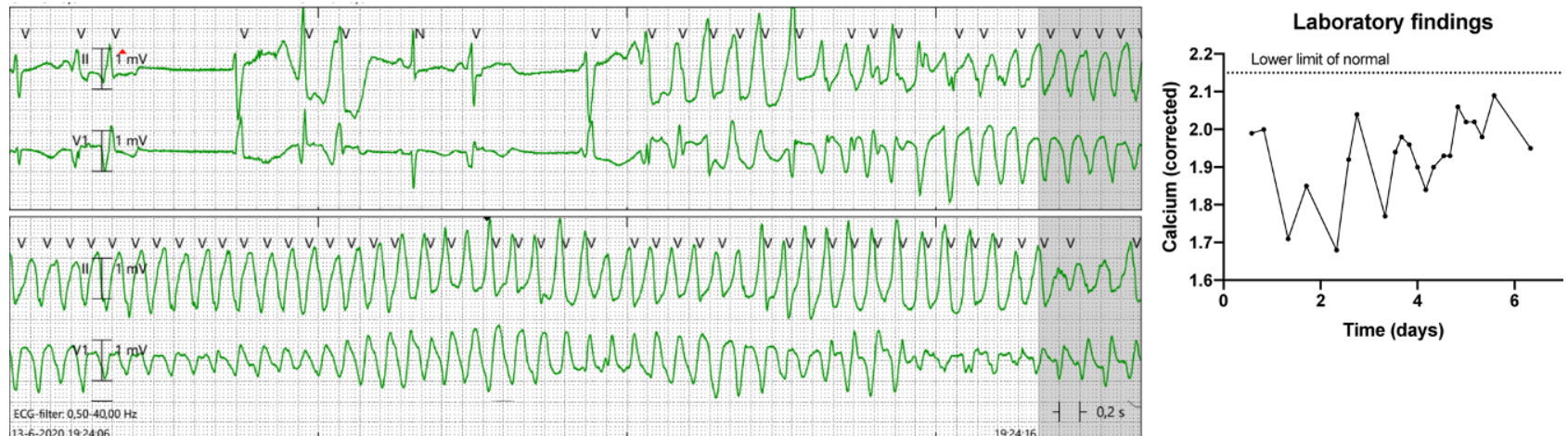

ECG-fiter $0.50-40.00 \mathrm{~Hz}$

Fig. 1 Upper Electrocardiogram demonstrating QT prolongation and ST-T changes attributable to hypocalcaemia.

Lower left Rhythm recording of the development of torsades

de pointes ventricular tachycardia. Lower right Graph depicting the serum calcium levels over time 